\title{
The art of cellular communication: tunneling nanotubes bridge the divide
}

\author{
Steffen Gurke • João F. V. Barroso • \\ Hans-Hermann Gerdes
}

Accepted: 5 March 2008 / Published online: 2 April 2008

(C) Springer-Verlag 2008

\begin{abstract}
The ability of cells to receive, process, and respond to information is essential for a variety of biological processes. This is true for the simplest single cell entity as it is for the highly specialized cells of multicellular organisms. In the latter, most cells do not exist as independent units, but are organized into specialized tissues. Within these functional assemblies, cells communicate with each other in different ways to coordinate physiological processes. Recently, a new type of cell-to-cell communication was discovered, based on de novo formation of membranous nanotubes between cells. These F-actin-rich structures, referred to as tunneling nanotubes (TNT), were shown to mediate membrane continuity between connected cells and facilitate the intercellular transport of various cellular components. The subsequent identification of TNTlike structures in numerous cell types revealed some structural diversity. At the same time it emerged that the direct transfer of cargo between cells is a common functional property, suggesting a general role of TNT-like structures in selective, long-range cell-to-cell communication. Due to the growing number of documented thin and long cell protrusions in tissue implicated in cell-to-cell signaling, it is intriguing to speculate that TNT-like structures also exist in vivo and participate in important physiological processes.
\end{abstract}

Keywords Tunneling nanotube $\cdot$ TNT .

Intercellular transfer $\cdot$ Cytoneme $\cdot$ Viral transmission

S. Gurke · J. F. V. Barroso · H.-H. Gerdes ( $\square)$

Department of Biomedicine, University of Bergen,

Jonas Lies vei 91, 5009 Bergen, Norway

e-mail: hans-hermann.gerdes@ biomed.uib.no

\author{
Abbreviations \\ TNT Tunneling nanotube \\ PD Plasmodesmata \\ PC12 Rat pheochromocytoma \\ NRK Normal rat kidney \\ DC Dendritic cells \\ EPC Endothelial progenitor cells \\ CM Cardiomyocytes \\ (E)GFP (Enhanced) Green fluorescent protein \\ EGFP-f Farnesylation signal of c-Ha-Ras fused to the \\ C-terminus of EGFP \\ GPI-GFP Glycosylphosphatidylinositol conjugated to GFP \\ MHC Major histocompatibility complex \\ HIV-1 Human immunodeficiency virus type 1 \\ MLV Murine leukemia virus
}

\section{Introduction}

Communication with the environment is a basic principle of any biological system. With the increasing complexity of higher organisms, cells had to evolve diverse mechanisms to exchange spatial and temporal information crucial for tissue organization and the maintenance of the organism as a whole. Certainly, tissues are not just a loose accumulation of individual cells, but a highly organized population of interacting cells. Thus, in the various types of animal and plant tissues, cell-to-cell communication is important for maintaining a supracellular organization. Probably the bestcharacterized example of such an organization is given by the animal central nervous system, which is composed of a complex network of interconnected neuron and glial cells. It is widely accepted that the complexity of the brain reflects its enormous number of intercellular links provided by synaptic connectivity (including gap junctions) between 
axons and dendrites. Gap junctions, through which molecules $<1 \mathrm{kDa}$ can penetrate, are also important players in establishing supracellular organization in other tissues containing electrically excitable cells as heart and smooth muscle cells. Furthermore, these proteinaceous channels interconnect cells of the multicellular layer forming epithelial tissues. Finally, cell-to-cell coupling via gap junctions is a general phenomenon during early embryogenesis, where most cells are electrically coupled. Perhaps due to the presence of a thick cell wall, plant cells have evolved thin membrane channels referred to as plasmodesmata (PD) to allow direct connections over longer distances (Baluška et al. 2004a; Cilia and Jackson 2004; Gallagher and Benfey 2005). Because these bridges provide both membrane and cytoplasmic connectivity between cells, plants are regarded as a supracellular assembly (Baluška et al. 2004b, c). PD, in addition to the functions known for gap junctions in animals, facilitate the transfer of ribonucleoparticles, transcription factors and viruses (Ruiz-Medrano et al. 2004).

In 2004, a new principle of cell-to-cell communication between animal cells, based on the formation of thin membrane channels, was reported (Rustom et al. 2004). These channels, referred to as tunneling nanotubes (TNT), were initially found in cultures of rat pheochromocytoma (PC12) cells. As PD, they were shown to mediate membrane continuity between connected cells. TNT permit the direct intercellular transfer of organelles, cytoplasmic molecules, and membrane components (Gerdes et al. 2007). Subsequent studies on other cell types revealed morphologically similar structures directing intercellular transfer of cargo, including pathogens. It thus becomes apparent that nanotubular bridges provide an important and general mechanism of cell-to-cell communication between animal cells. In the following, we summarize the current knowledge and development in the field of nanotubular communication. As awareness of the potential physiological implications of these structures, we will give a short overview on published data describing long and thin cellular protrusions in tissue implicated in cellular communication.

\section{Diversity of TNT-like structures}

TNT connecting PC12 cells are typically $50-200 \mathrm{~nm}$ in diameter and can reach lengths up to several cell diameters. They are stretched, interconnecting cells at their nearest distance (Fig. 1) (Hodneland et al. 2006; Rustom et al. 2004). Their structural integrity is sensitive to mechanical stress, chemical fixation, and even to prolonged light exposure. The feature that most strikingly distinguishes TNT from other cellular protrusions is that they hover in the medium and have no contact to the substratum (Fig. 1a, $\mathrm{a}_{1}$ ). A structural characterization of TNT between PC12 cells revealed that they contain F-actin as a prominent cytoskeleton element but no microtubules (Table 1). Further characterization at the ultra-structural level showed a seamless transition of the surface membrane of the TNT with the plasma membranes of the connected cells (Fig. 1b, $b_{1}, b_{2}$ ). In addition, a continuous membrane with both connected cells was evident in transmission electron micrographs (Fig. 2a, $\mathrm{a}_{1}, \mathrm{a}_{2}$ ) (Table 1). These observations, together with the documentation of a limited lateral diffusion of fluorescent membrane proteins occurring between the plasma membranes of TNT-connected cells, led to the proposal that TNT mediate intercellular membrane continuity (Fig. 3a) (Gerdes et al. 2007; Rustom et al. 2004).

Based on the morphological criteria defined for PC12 cells, similar TNT-like connections were subsequently identified for several permanent cell lines and primary cultures (for a comprehensive overview see (Gerdes et al. 2007))
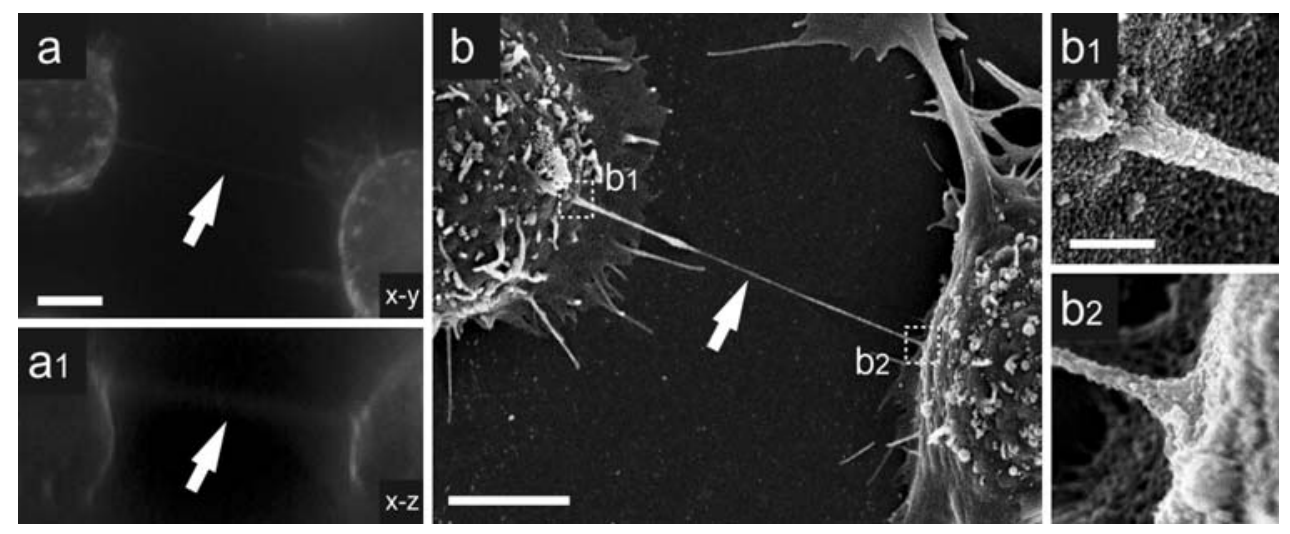

Fig. 1 Architecture of TNT between cultured PC12 cells. (a) 3D fluorescence image ( $(x-y)$-maximum projection of 40 consecutive $400 \mathrm{~nm}$ sections) of a wheat germ agglutinin-stained TNT connecting two live PC12 cells. $\left(\mathbf{a}_{1}\right)(x-z)$-projection in the plane of the TNT indicated in (a). (b) Scanning electron micrograph (SEM) showing the ultra-struc- ture of a TNT between two PC12 cells. The boxed areas are shown as higher magnification images $\left(\mathbf{b}_{1}, \mathbf{b}_{2}\right)$. Modified from Rustom et al. (2004) Science 303:1007-1010. Scale bars, a, a $\mathbf{a}_{1}, \mathbf{b}, 5 \mu \mathrm{m} ; \mathbf{b}_{1}, \mathbf{b}_{2}$, $500 \mathrm{~nm}$ 
Table 1 TNT-like structures in vitro ${ }^{\mathrm{a}}$

\begin{tabular}{|c|c|c|c|}
\hline \multirow[t]{2}{*}{ Cell type } & \multicolumn{3}{|l|}{ TNT-like structures } \\
\hline & $\begin{array}{l}\text { Cytoskeletal } \\
\text { components }\end{array}$ & $\begin{array}{l}\text { Membrane } \\
\text { continuity/ } \\
\text { "open-ended" }\end{array}$ & Cargo \\
\hline PC12 cells (Rustom et al. 2004) & F-actin, myosin Va & $(+)^{\mathrm{b}}$ & $\begin{array}{l}\text { Endosome-related organelles, } \\
\text { lipid-anchored proteins (EGFP-f), } \\
\text { EGFP-actin }\end{array}$ \\
\hline NRK cells (Rustom et al. 2004) ${ }^{\mathrm{c}}$ & $(\mathrm{F} \text {-actin, myosin } \mathrm{Va})^{\mathrm{c}}$ & ND & Endosome-related organelles \\
\hline $\begin{array}{l}\text { EBV-transformed human } \\
\text { B cell line (721.221) } \\
\text { (Önfelt et al. 2004) }\end{array}$ & ND & ND & $\begin{array}{l}\text { GPI-GFP, (HLA-Cw6-GFP, } \\
\text { in coculture with human } \\
\text { peripheral blood } \\
\text { Natural Killer cells) }^{\mathrm{d}}\end{array}$ \\
\hline $\begin{array}{l}\text { Between neonatal rat CM and adult } \\
\text { human EPC (Koyanagi et al. 2005) }\end{array}$ & ND & ND & $\begin{array}{l}\text { Mitochondria, } \\
\text { soluble proteins (GFP) }\end{array}$ \\
\hline $\begin{array}{l}\text { Primary cultures of rat astrocytes } \\
\text { (Zhu et al. 2005) }\end{array}$ & F-actin, myosin Va & ND & ND \\
\hline DC (Watkins and Salter 2005) & ND & $(+)^{\mathrm{e}}$ & $\begin{array}{l}\text { Calcium fluxes, } \\
\text { surface receptors } \\
\text { (HLA-A,B,C class I MHC) }^{\mathrm{d}}\end{array}$ \\
\hline $\begin{array}{l}\text { THP-1 monocytes } \\
\quad \text { (Watkins and Salter 2005) }\end{array}$ & F-actin & $(+)^{\mathrm{e}}$ & $\begin{array}{l}\text { Calcium fluxes, the fluid phase } \\
\text { marker lucifer yellow, } \\
\text { surface receptors } \\
\text { (HLA-A,B,C class I MHC) }^{\mathrm{d}}\end{array}$ \\
\hline $\begin{array}{l}\text { Between DC and THP-1 monocytes } \\
\text { (Watkins and Salter 2005) }\end{array}$ & ND & $(+)^{\mathrm{e}}$ & Calcium fluxes \\
\hline $\begin{array}{l}\text { Human monocyte-derived macrophages } \\
\quad \text { (bridges with diameter } \geq 0.7 \mu \mathrm{m} \text { ) } \\
\quad \text { (Önfelt et al. 2006) }\end{array}$ & F-actin, microtubules & $(+)^{\mathrm{f}}$ & $\begin{array}{l}\text { Mitochondria, } \\
\text { endosome-related } \\
\text { organelles, lysosomes }\end{array}$ \\
\hline $\begin{array}{l}\text { Human monocyte-derived macrophages } \\
\text { (nanotubes with diameter }<0.7 \mu \mathrm{m} \text { ) } \\
\text { (Önfelt et al. 2006) }\end{array}$ & F-actin & ND & $\begin{array}{l}\text { Surfing Mycobacterium } \\
\text { bovis bacillus } \\
\text { Calmette-Guérin }\end{array}$ \\
\hline $\begin{array}{l}\text { Cos- } 1, \mathrm{XC} \text { and HEK } 293 \text { cells } \\
\quad \text { (Sherer et al. 2007) }\end{array}$ & F-actin & $(-)^{\mathrm{b}}$ & MLV \\
\hline Jurkat T cells (Sowinski et al. 2008) & F-actin & $(-)^{\mathrm{b}, \mathrm{e}}$ & HIV-1 protein Gag \\
\hline
\end{tabular}

a Only those publications that fulfill at least one of the listed criteria are shown

b Accessed by electron microscopy

c Gurke, S., Barroso, J., Bukoreshtliev, N., Gerdes, H.-H., unpublished data

${ }^{d}$ These molecules were shown to localize in TNT-like structures, but their intercellular transfer was not proven

e Accessed by the measurement of calcium fluxes

${ }^{\mathrm{f}}$ Proposed from the observation of a seamless transition between microtubules of the bridge with microtubular networks of both connected cells ND: not determined

(Table 1). TNT-like bridges between dendritic cells (DC) (Watkins and Salter 2005) and perhaps also those connecting neonatal rat cardiomyocytes (CM) and adult human endothelial progenitor cells (EPC) (Koyanagi et al. 2005), appear to be most closely related to the TNT described for PC12 cells. The flow of cytoplasmic molecules suggests membrane continuity between connected cells (Table 1). This contrasts the TNT-like bridges between T cells, which have been characterized lately in considerable detail (Sowinski et al. 2008). The observed T-cell nanotubes have an average length of $\sim 20 \mu \mathrm{m}$, a diameter of $180-380 \mathrm{~nm}$, and are not tethered to the substratum. Moreover, as in PC12 cells, only F-actin but not microtubules were detected in T-cell nanotubes (Fig. 3). However, despite the overall similarity in architecture and capacity to facilitate intercellular transfer of cargo between nanotubes of PC12 cells, DC, CM/EPC and T-cells, the latter do not mediate membrane continuity between connected cells (Fig. 2b, $b_{1}, b_{2}$ ) (Table 1). This was concluded from the observation that nanotubes between T-cells (i) do not facilitate the transfer of cytoplasmic molecules, (ii) do not permit free diffusion of fluorescent plasma membrane components and (iii) display a junctional border between the nanotube and the connected T-cell at the ultra-structural level (Fig. 2 $b_{1}$ ). Accordingly, they were classified as "not open- 


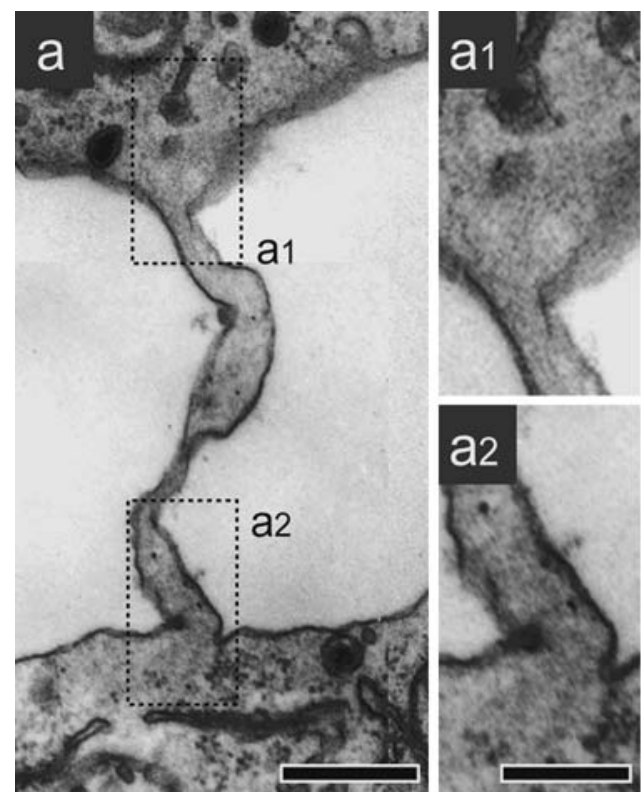

Fig. 2 Transmission electron micrographs (TEM) showing the ultrastructure of distinct TNT-like bridges in different cell types. (a) Openended TNT connecting two PC12 cells reconstructed from images of two consecutive $80 \mathrm{~nm}$ sections. The boxed areas are shown as higher magnification images $\left(\mathbf{a}_{1}, \mathbf{a}_{2}\right)$. A continuous membrane is observed between the nanotube and the plasma membrane of the two connected cells. Modified from Rustom et al. (2004) Science 303:1007-1010. (b)

ended" cellular nanotubes (Fig. 3b). Other identified closeended nanotubular bridges that share some morphological features with TNT are murine leukemia virus-induced "filopodial bridges" (Sherer et al. 2007) (Table 1).

Interestingly, it has been shown that different classes of nanotubes exist even within a single cell type. In the case of macrophages, not only thin, F-actin-containing bridges similar to other TNT-like structures were detected, but also a thicker type of cellular connection $(\geq 0.7 \mu \mathrm{m}$ diameter), which contained both F-actin and microtubules (Önfelt et al. 2006). This thicker type of connection was suggested to be open ended due to a seamless transition of the microtubules inside the bridge with the microtubular networks of both connected cells (Önfelt et al. 2006) (Table 1). Thin, and thicker microtubule-containing connections were also found between prostate cancer cells (Vidulescu et al. 2004).

Finally, another type of long and thin F-actin-containing cellular protrusions that share striking features with TNTlike intercellular bridges, are cytonemes. These membrane nanotubes were discovered in Drosophila imaginal wing discs, emanating from the periphery of the columnar cell sheet toward the signaling center associated with the anterior/posterior border (Ramírez-Weber and Kornberg 1999). They are thought to extend toward the target cells by chemotaxis (Ramírez-Weber and Kornberg 1999) (Fig. 3c) to accomplish the receptor-mediated uptake of the secreted morphogen Decapentaphlegic (Dpp) during spatial pattern-

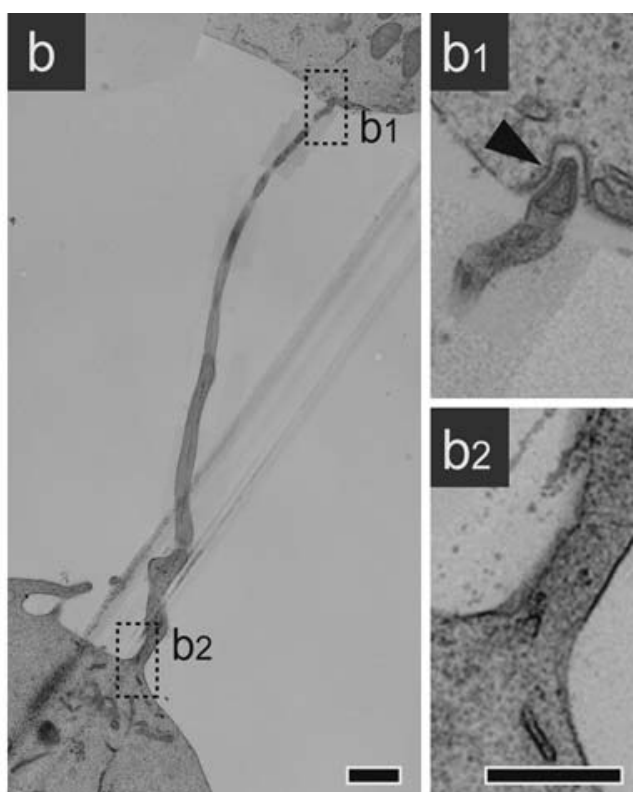

Close-ended TNT-like bridge connecting two T cells and displaying a junctional border, reconstructed from images of 13 consecutive $60 \mathrm{~nm}$ sections. The boxed areas are shown as higher magnification images $\left(\mathbf{b}_{1}, \mathbf{b}_{2}\right)$. The nanotube formed by one cell $\left(\mathbf{b}_{2}\right)$ protrudes into an invagination (arrowhead) of the connected cell $\left(\mathbf{b}_{1}\right)$. Modified from Sowinski et al. (2008) Nat Cell Biol 10:211-219. Scale bars, a, b, $1 \mu \mathrm{m} ; \mathbf{a}_{1}$, $\mathbf{a}_{2}, \mathbf{b}_{1}, \mathbf{b}_{2}, 500 \mathrm{~nm}$

ing (Hsiung et al. 2005). Once endocytosed, the morphogen is thought to be delivered to the cell body by retrograde transport along the cytoneme (Fig. $3 \mathrm{c}_{1}$ ). Thus, these structures are proposed to fulfill an important task in long-range cell-to-cell signaling during embryonic development. In contrast to TNT-like structures, cytonemes have not been shown to physically bridge cells. Nevertheless, functionally similar structures, emanating from tracheal cells in response to Branchless (Bnl)-Fibroblast Growth Factor (FGF) signaling, appear to do so (Sato and Kornberg 2002).

The identification of TNT-like structures in cell cultures has been mainly based on the morphological criteria defined for PC12 cells (Rustom et al. 2004). In some cases, a proper comparison was hindered by their limited characterization. Nonetheless, heterogeneity regarding formation, structure, and functional properties across cell types and even within a given cell type has emerged (Table 1). Certainly, more detailed information is necessary for a proper classification of all these structures and thus, as things are now, we shall refer to them as TNT-like structures, irrespective of whether membrane continuity was observed.

\section{Formation of TNT-like structures}

TNT-like structures form de novo between cells on a timescale of several minutes by apparently two distinct mecha- 
Fig. 3 Schematic representations of three distinct nanoscaled cellular protrusions and proposed modes of cell-to-cell communication. (a) A TNT-

mediating membrane continuity between cells. $\left(\mathbf{a}_{1}\right)$ Organelles like endocytic vesicles and mitochondria are transported unidirectionally between cells by an actin-dependent mechanism. (b) Nanotubular bridge between cells displaying a junctional border. $\left(\mathbf{b}_{1}\right)$ Distinct viral particles are transported either at the surface of the nanotube by a receptor-dependent mechanism using actin retrograde flow or inside the cellular nanotube by an actin-dependent mechanism. (c) Cellular nanotube (cytoneme) extending toward a target cell by chemotaxis. $\left(\mathbf{c}_{1}\right)$ Signaling molecules secreted by the target cell are proposed to be endocytosed by a receptor-mediated mechanism at the tip of the cytoneme and transported in a retrograde manner toward the cell body of the receiving cell. The arrows $(\mathbf{a}-\mathbf{c})$ indicate the direction of transfer
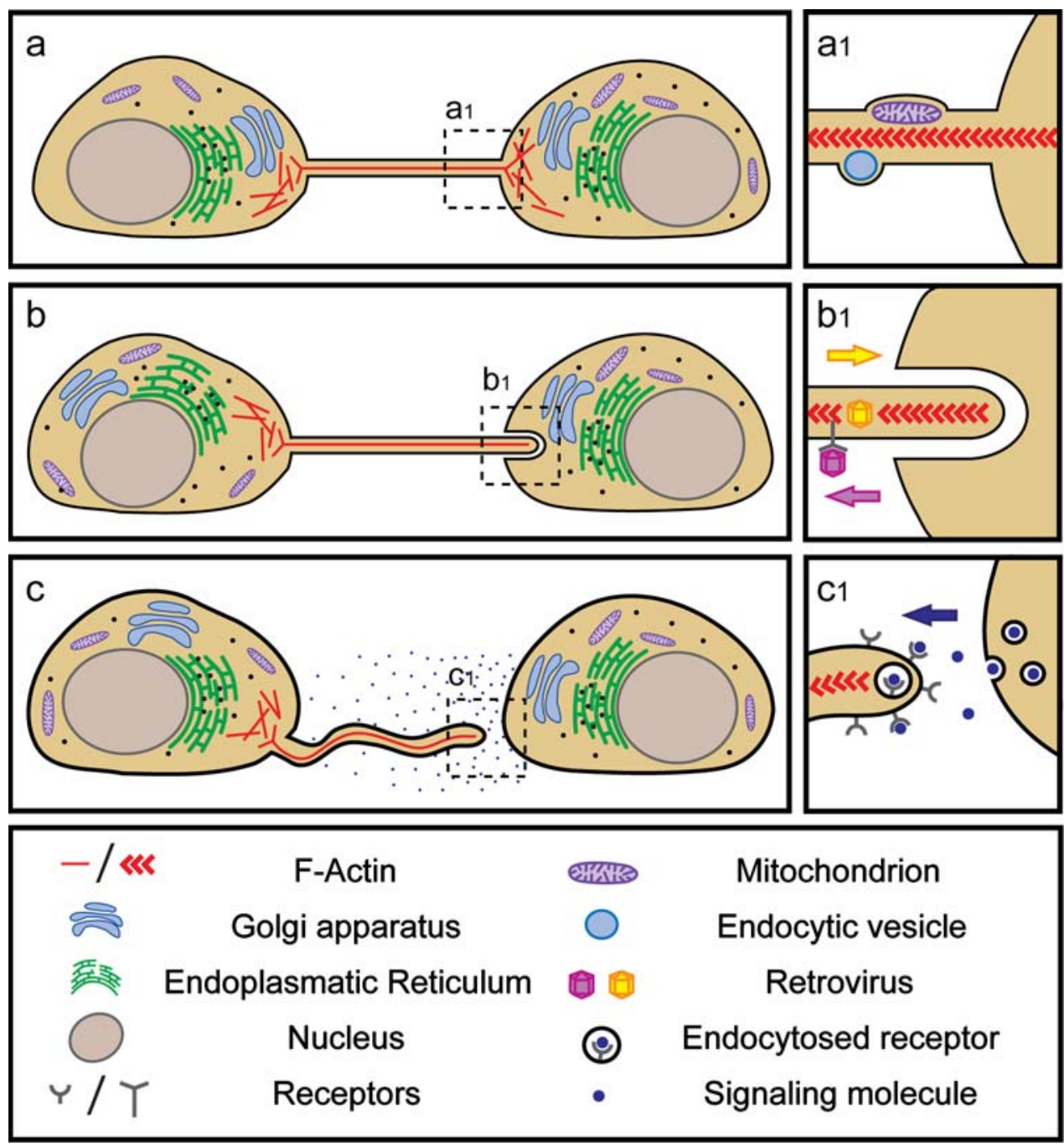

nisms. With respect to the first mechanism, initial studies on PC12 cells showed that TNT could be established by a seemingly directed outgrowth of swaying filopodia-like protrusion(s) toward a neighboring cell. Once contact is made, a single dilated and bended bridge is often observed along with the degeneration of remainder protrusions. This bended structure is then remodeled into a straight and thin bridge showing the characteristic morphology of typical TNT (Rustom et al. 2004). One can speculate that the seemingly directed filopodia outgrowth preceding TNT formation is under control of chemotactic guidance. Evidence for this is provided for related processes like the formation of cytonemes toward a Bnl-FGF gradient in in vitro cultures of Drosophila cells (Ramírez-Weber and Kornberg 1999) (Fig. 3c) or murine leukemia virus (MLV)-induced nanotubular bridges emanating from non-infected fibroblast cells toward infected cells (Sherer et al. 2007). The observation that TNT-like bridges also emerge when attached PC12 (Rustom et al. 2004) or immune cells (Önfelt et al. 2004, 2006; Sowinski et al. 2008) depart from each other, led to the proposal of a second mechanism of TNT formation (Gerdes et al. 2007; Önfelt et al. 2004), which a priori excludes any dependence on chemotactic guidance of filopodia. Subsequent detailed studies on $\mathrm{T}$ cells revealed that cell-to-cell interaction for at least a few minutes before dislodging is required for successful nanotubular bridge formation (Sowinski et al. 2008). It is of note that, in contrast to PC12 cells, a filopodium-dependent mechanism of nanotubular bridge formation between immune cells was not reported to date (Önfelt et al. 2004, 2006; Sowinski et al. 2008).

Actin polymerization is thought to be a key event for both mechanisms of TNT formation (Gerdes et al. 2007). It drives filopodia outgrowth important in the first mechanism and is most probably important for the stabilization of TNT-like structures emerging by the second mechanism. In support of this, TNT formation is not observed in the presence of actin-depolymerizing drugs (Rustom et al. 2004), and TNT-like structures between T cells only form if the cells diverge with a speed below that of processes driven by 
actin polymerization (Cameron et al. 1999; Sowinski et al. 2008). Zhu et al. (2005) obtained further evidence that actin polymerization and TNT formation are linked by demonstrating their concurrent induction by $\mathrm{H}_{2} \mathrm{O}_{2}$ in primary cultures of rat astrocytes.

TNT-like structures have a dynamic nature leading to only transient bridges as observed in in vitro cultures. The nanotubular bridges between T cells (Sowinski et al. 2008), PC12 cells or normal rat kidney (NRK) cells (Bukoreshtliev, N., Gerdes, H.-H., unpublished data) have variable lifetimes, ranging from a few minutes to less than $60 \mathrm{~min}$ for the former and even up to several hours for the latter two. These considerable differences in lifetime, even at the cellular level, may reflect the existence of different subclasses of TNT-like structures. It is interesting to speculate that the fusion of the nanotube with the plasma membrane of the connected cell is part of a time-dependent maturation step leading to such heterogeneity.

Studies on model artificial membrane tubes such as those created by pulling tethers from synthetic lipid vesicles or cellular plasma membrane provide a complementary approach to obtain mechanistic insights into the formation of TNT-like structures. The morphology of such nanotubes resembles that of TNT-like structures and it seems plausible that the same physical laws govern the formation and architecture of both structures. The exploitation of such in vitro models revealed that the elongation of plasma membrane nanotubes requires a membrane flow from the cell plasma membrane into the growing tube. It is suggested that cells maintain a membrane reservoir (e.g. ruffles, invaginations), controlled by the cytoskeleton, to provide a buffer against membrane tension over several micrometers of tube elongation (Raucher and Sheetz 1999; Sun et al. 2005). Thus, the available membrane reservoir may restrict the number, total length, and lifetime of TNTlike connections for a given cell.

\section{TNT-like structures are conduits for the delivery of cargo}

An obvious advantage of establishing direct bridges between cells is an improvement in selective communication even over long distances. In agreement with this assumption, the common feature of all TNT-like structures characterized in more detail, is the transfer of cargo between connected cells (Table 1).

\section{Cellular components}

Direct evidence for the intercellular exchange of cargo via TNT-like structures was obtained by video-microscopic studies. By employing fluorescent dyes, organelles belong- ing to the endosomal/lysosomal system (Rustom et al. 2004) (Gurke, S., Gerdes, H.-H., unpublished data) as well as mitochondria (Koyanagi et al. 2005) were shown to traffic uni-directionally along TNT-like structures between cells over long distances (Fig. $3 a_{1}$ ) (Table 1). The occurrence of an intercellular transfer of organelles raises the question as to what kind of information is transferred and how this information is integrated in the target cell. In the case of the endosomal system, early endocytic vesicles are particularly interesting candidates for TNT-mediated delivery. These organelles are one of the major reloading points for a variety of signaling complexes resulting from the endocytosis of activated cell surface receptors (Miaczynska et al. 2004). Once delivered to the target cells, the transferred endocytic vesicles are able to fuse with their counterparts (Rustom et al. 2004), and provide a potential way to integrate information. In essence, the transfer of endocytic organelles propagates signaling information from the single cell to a larger community, which may lead to coordinated cell behavior. Mitochondria were shown to transfer via TNT from neonatal rat CM to adult human EPC and it was suggested that this event could contribute to the acquisition of a cardiomyogenic phenotype by the progenitor cells (Koyanagi et al. 2005) (Fig. 4). Moreover, the active transfer of this organelle from adult stem cells and somatic cells to mammalian cells with non-functional mitochondria was shown to rescue aerobic respiration in the latter (Csordás 2006; Spees et al. 2006). The obtained data are consistent with a TNT-related delivery, although alternative mechanisms were not excluded.

In addition to the transfer of organelles, plasma membrane components such as lipid-anchored proteins can laterally transfer along the TNT-like bridge into the plasma

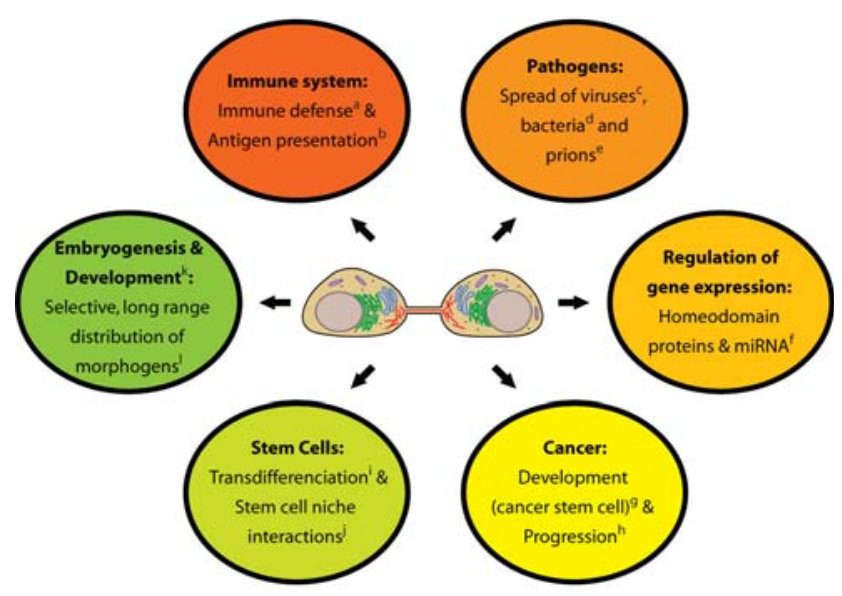

"(Watkins and Salter 2005); '(Groothuis et al. 2005; Önfelt et al. 2004; Watkins and Salter 2005; Williams et al. 2007); ' (Sherer et al. 2007; Sowinski et al. 2008); '(Önfelt et al. 2006); '(Magalhāes et al. 2005); ${ }^{\text {f }}$ (Gerdes et al. 2007); '(Bjerkvig et al. 2005; Ratajczak et al. 2006; Tysnes and Bjerkvig 2007); ' (Ambudkar et al. 2005; Levchenko et al. 2005); '(Kajstura et al. 2006; Koyanagi et al. 2005); '(Freund et al. 2006); ' (Guo and Zheng 2004); '(Demontis 2004)

Fig. 4 Emerging physiological implications of TNT-like structures 
membrane of connected cells. This was demonstrated for both the inner and outer leaflets of the plasma membrane by using glycosylphosphatidylinositol conjugated to GFP (GPI)-GFP (Önfelt and Davis 2004; Önfelt et al. 2004) and the farnesylation signal of c-Ha-Ras fused to the C-terminus of EGFP (EGFP-f) (Rustom et al. 2004), respectively (Table 1). Such a transport is consistent with membrane continuity between connected cells. Surface receptors could also be transferred directly by lateral diffusion in the plane of the cell surface, in addition to an endosome-dependent delivery. Interestingly, the transfer of membrane proteins between myeloid cells was found to involve scavenger receptors (Dr. R. D. Salter, Univ. of Pittsburgh, personal communication). It is of note that major histocompatibility complex (MHC) class I receptors were detected at the entire length of TNT-like bridges connecting immune cells (Önfelt et al. 2004; Watkins and Salter 2005). This points to a key role of TNT in a faster and more efficient presentation of antigens, in particular at the immunological synapse (Groothuis et al. 2005; Williams et al. 2007) (Fig. 4), defined as a highly specialized interface between immune cells (Norcross 1984; Paul and Seder 1994). In this case, the lateral transfer of only a few molecules can fulfill important roles in a coordinated immune response. Interestingly, in analogy to TNT, membrane continuity was found at the immunological synapse (Stinchcombe et al. 2001). The characterized "membrane bridges" had a diameter of $50-95 \mathrm{~nm}$ as observed by electron microscopy (Stinchcombe et al. 2001).

Finally, the proposed model of membrane continuity suggests a cytoplasmic bridge in analogy to $\mathrm{PD}$, which permits the free flow of soluble molecules up to a certain size limit defined by the free space along the interior of the nanotube. In support of this view, EGFP-actin was transferred between TNT-connected PC12 cells (Rustom et al. 2004), GFP between CM and EPC (Koyanagi et al. 2005), and the fluid phase marker Lucifer yellow between THP-1 monocytes (Watkins and Salter 2005) (Table 1). Notably, both GFP and the small dye molecule calcein, with a molecular weight of $400 \mathrm{Da}$, were apparently impeded to diffuse passively between TNT-connected PC12 cells (Rustom et al. 2004). Thus, TNT-like structures, like PD, may have a variable size exclusion limit depending on the cell type (Gerdes et al. 2007). With regard to soluble markers, certainly the most physiologically relevant finding was the TNT-dependent propagation of calcium signals between THP-1 monocytes as well as from DC to THP-1 monocytes (Watkins and Salter 2005) (Table 1). Stimulation by contact or exogenous soluble stimulators of both DC and THP-1 monocytes led to a calcium flux that propagated through a network of TNT-connected cells up to $500 \mu \mathrm{m}$ away from the point of stimulation. The elicited calcium wave propagated uni-directional with an initial speed of $35 \mu \mathrm{m} / \mathrm{s}$ that slowed down rapidly to $10-15 \mu \mathrm{m} / \mathrm{s}$ (Watkins and Salter 2005). This rather low and rapidly decreasing speed supports a TNT-mediated signal spread along the cellular network, which is driven by a chemical gradient rather than an action potential. Such a view also corroborates a TNT-mediated membrane continuity providing a cytoplasmic bridge between connected cells (Table 1). Most remarkably, the transfer of calcium ions through TNT led to the flattening and membrane extension of the receiving cells, as occurs during physiological responses in preparation for phagocytosis (Watkins and Salter 2005). Thus, this study provided the first evidence for functional connectivity accomplished by TNT and suggests a crucial role of these structures in immune defense (Fig. 4).

\section{Pathogens}

An emerging topic is the efficient spread of pathogens, like bacteria and mammalian viruses, along cell membrane protrusions (Figs. 3, 4). By using established or induced nanotubular connections between cells, pathogens circumvent the rate-limiting step of diffusion and efficiently accelerate their spreading (Sherer et al. 2007; Sowinski et al. 2008). Among the viruses shown to exploit cellular protrusions to transfer from cell-to-cell are the vaccinia virus (Cudmore et al. 1995,. 1996), pseudorabies virus (Favoreel et al. 2005, 2006), the herpes simplex virus (La Boissière et al. 2004), MLV (Sherer et al. 2007) and human immunodeficiency virus type 1 (HIV-1) (Sowinski et al. 2008). In the following, we will focus on the latter two, which were characterized in much detail and gave rise to two different mechanisms of virus transmission.

Sowinski et al. (2008) proposed membrane nanotubes between $\mathrm{T}$ cells as a new route for HIV-1 transmission (Fig. $3 b_{1}$ ), in addition to cellular contact points known as virological synapses (Jolly et al. 2004; Jolly and Sattentau 2004; Sol-Foulon et al. 2007). Using a recombinant HIV-1 expressing Gag-GFP, they demonstrated its uni-directional move through innate nanotubular bridges and subsequent transmission into connected T cells (Sowinski et al. 2008) (Table 1). Furthermore, the requirement of cell surface receptors for viral transmission implied, in agreement with ultra-structural data, a junctional border between the nanotube and the connected $\mathrm{T}$ cell. It should be emphasized that the transmission of HIV-1 through nanotubular bridges can minimize the exposure of the virus to extracellular antibodies or complement. However, a nanotube-dependent spread may open new avenues in the development of antiviral drugs.

A different, even though nanotube-dependent, mechanism of transmission was reported for MLV (Sherer et al. 2007). The cell-to-cell transmission of MLV was directly visualized by infecting cultured cells with a recombinant 
virus expressing the viral capsid protein Gag and the envelope protein Env as a fusion construct with fluorescent proteins. MLV induces the outgrowth of thin and long filopodia from uninfected cells toward infected cells (Sherer et al. 2007). These filopodia are proposed to stably anchor to the cell body of an infected cell by viral envelope glycoprotein (Env)/receptor interactions. Subsequently, MLV moves along the outer surface of these nanotubular bridges to reach the cell body of target cells, where it finally enters (Sherer et al. 2007) (Fig. 3 $b_{1}$ ). In addition to viruses, bacteria were reported to surf along TNT-like structures connecting macrophages (Önfelt et al. 2006) (Table 1).

\section{Mechanism of transfer}

It is possible that more than one transfer mechanism for shipping cargo via TNT-like bridges has evolved considering their structural diversity and the multitude of transferred cargo. For organelles and viruses, an F-actindependent, uni-directional transport prevails (Fig. 3), with the exception of a microtubule-dependent, bi-directional movement of organelles in thick bridges connecting macrophages (Önfelt et al. 2006). In the case of endocytic organelles, an acto-myosin-dependent transport system is presumed (Fig. $3 \mathrm{a}_{1}$ ) due to the presence of the barbed-end directed actin-specific motor myosin Va in TNT (Rustom et al. 2004; Zhu et al. 2005) (Bukoreshtliev, N., Gerdes, H.-H., unpublished data) (Table 1) partially co-localizing with the respective organelles (Rustom et al. 2004). This model is supported by the low transport velocity in the range of actin-dependent transport (Rustom et al. 2004) and implies that the F-actin fibers inside the bridge have the same polarity. Also HIV-1 particles were suggested to move in an actin-dependent manner through nanotubular bridges (Sowinski et al. 2008) (Fig. 3b ) $_{1}$. Interestingly, even in the case of MLV surfing along filopodia bridges with a speed $\sim 7$ times slower as compared to that of HIV-1 within the bridges, an acto-myosin transfer mechanism appears to be in place (Sherer et al. 2007). This results in the uni-directional movement of all viral particles from infected to target cells, presumably using myosin II controlled retrograde flow of actin and cognate Env-receptor interactions (Fig. $3 b_{1}$ ). In contrast to organelles and viruses, the unidirectional propagation of calcium waves is likely to be driven by a chemical gradient rather than an active transport mechanism. Passive diffusion is likely to control the transfer of other small cytoplasmic molecules and also some plasma membrane components, if membrane continuity is present.

Regarding the modality by which shipped cargo enters the target cell, two different scenarios are conceivable. In the case of membrane continuity as observed in PC12 cells, an open-ended transport along cytoskeleton elements without border crossing is envisaged, consistent with the observed uniform movement of transferred organelles (Rustom et al. 2004). In analogy to PD, gating mechanisms may exist to control this open-ended transport (Gerdes et al. 2007). In the case of close-ended cell-to-cell bridges containing junctional borders, as are the innate nanotubes connecting T cells and the MLV-induced cellular bridges, the cargo has to traverse the plasma membrane boundary. This is consistent with the finding that a receptor-dependent transmission of HIV-1 Gag could be blocked by the HIV-1 fusion inhibitor T20 (Sowinski et al. 2008).

\section{Ultra-fine cellular extensions in tissue}

Does intercellular communication mediated by TNT-like structures play a physiological role in tissue? This is probably the most interesting and important question that needs to be addressed in the near future. The absence of a TNTspecific marker does not allow an explicit answer to this question yet. However, studies employing cell cultures already point to important physiological implications of TNT-like structures in intercellular communication (reviewed in Gerdes et al. (2007)) (Fig. 4). It could be argued that cell culture models are rough representations of physiological systems and that TNT-like structures are the sole result of stress conditions in this in vitro situation. However, the widely documented richness of cellular protrusions in tissue implicated in intercellular communication (Rørth 2003) (Table 2) disagrees with such a possibility and instead supports an in vivo function. Cellular extensions have been documented in diverse tissues and during various physiological processes such as embryogenesis, stem cell differentiation, cell migration, and wound healing.

The formation of cellular extensions ("pseudopods") during embryogenesis became first evident by studying sea urchin morphogenesis (Gustafson and Wolpert 1967; Miller et al. 1995), suggesting a function of these structures in force generation or cell recognition. During subsequent studies over the last decades, a variety of similar cellular extensions were found to be associated with developmental processes. Interestingly, most of them appear to be actinrich as TNT-like structures. The Drosophila wing imaginal disc provides an attractive system for studying cell protrusions within a developing tissue. The first described example of such protrusions were the F-actin-containing cytonemes extending from the periphery of the columnar cell sheet toward the signaling center within this layer (Ramírez-Weber and Kornberg 1999). This discovery inspired further studies describing other cellular protrusions in the wing disc extending not only within (Chou and Chien 2002; Demontis and Dahmann 2007) but also between cell 


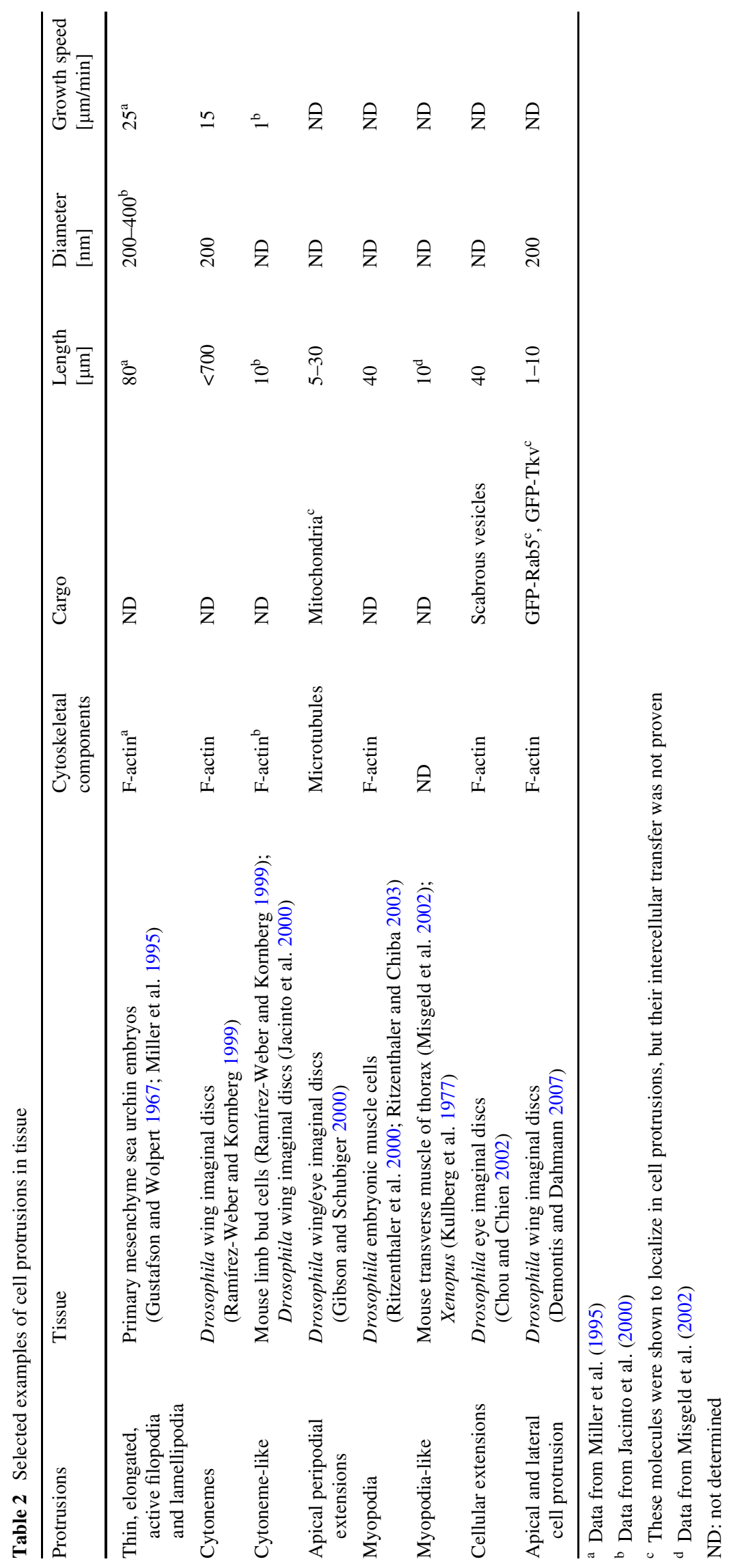


layers (Demontis and Dahmann 2007; Gibson and Schubiger 2000). In a very recent study on live wing discs, Demontis and Dahmann (2007) observed two new types of cellular extensions, i.e. lateral protrusions interconnecting distant cells of the columnar epithelium, and protrusions of the apical surface connecting to the squamous epithelium. Furthermore, ectopically expressed GFP-actin and the early endosome marker GFP-Rab 5 were detected inside these protrusions, resembling the finding made for TNT-like structures between cultured cells. These different protrusions may be involved in the intercellular signaling necessary for growth and patterning of wing imaginal discs (Demontis and Dahmann 2007).

Thin, actin-based membrane extensions were also found to be crucial for embryonic dorsal closure in Drosophila (Jacinto et al. 2000). Data obtained by confocal imaging of living fly embryos suggest that these long protrusions participate in both the mechanics of epithelial adhesion and in the search for a correct partner within the opposing epithelium. Likewise, related fundamental processes such as gastrulation, neural crest closure (Bard 1992), and wound healing (Wood et al. 2002) seem to involve similar actinrich membrane extensions.

Other examples of actin-based cellular extensions during development are the so-called myopodia in Drosophila embryonic muscle cells that can be observed in whole mount. These dynamic postsynaptic microprocesses, with lengths up to $40 \mu \mathrm{m}$ and highly sensitive to photoillumination, cluster at the site of motoneuron innervation while interacting with presynaptic filopodia. It was proposed that they play a role in the process of synaptic target recognition by contributing to direct long-distance cellular communication (Ritzenthaler et al. 2000; Ritzenthaler and Chiba 2003). Importantly, similar structures have been described in Xenopus (Kullberg et al. 1977) and mouse (Misgeld et al. 2002).

Finally, long, thin cellular extensions are also associated with guided cellular migration during development (Ribeiro et al. 2002; Sato and Kornberg 2002), immune defense such as the migration of macrophages through the endothelial cell layer (Blue and Weiss 1981) and tumor cell invasion (Vignjevic and Montagnac 2008). Certainly, there are many more examples of long cellular nanotubes in tissue involved in cellular communication besides the ones listed here (Table 2). This suggests that extensions in tissue are a rather common feature and that cells in culture preserve the ability to form similar, physiologically relevant structures. But, an important question remains: Do TNT-like structures, observed in cell culture models, have mechanistically and/or functionally related counterparts in live tissue? Furthermore, with respect to TNT, which have been found to mediate membrane continuity between cultured cells, it will be of foremost interest to find out, if this type of connection also exists in vivo.
Acknowledgments We thank Simone Reber for her contribution to the manuscript and all group members for stimulating discussions. Furthermore, we are grateful to Dr. Salter, University of Pittsburgh, for providing unpublished data. This work is being supported by the Norwegian Research Council (HHG), the Norwegian Cancer Society (JFVB, HHG), the University of Bergen, Norway (HHG), and the Gottlieb Daimler- and Karl Benz-Foundation, Germany (SG).

\section{References}

Ambudkar SV, Sauna ZE, Gottesman MM, Szakacs G (2005) A novel way to spread drug resistance in tumor cells: functional intercellular transfer of P-glycoprotein (ABCB1). Trends Pharmacol Sci 26:385-387

Baluška F, Hlavacka A, Volkmann D, Menzel D (2004a) Getting connected: actin-based cell-to-cell channels in plants and animals. Trends Cell Biol 14:404-408

Baluška F, Volkmann D, Barlow PW (2004b) Cell bodies in a cage. Nature 428:371

Baluška F, Volkmann D, Barlow PW (2004c) Eukaryotic cells and their Cell Bodies: Cell Theory revised. Ann Bot (Lond) 94:9-32

Bard J (1992) Morphogenesis: the cellular and molecular processes of developmental anatomy. Cambridge Univ Press, Cambridge, U.K

Bjerkvig R, Tysnes BB, Aboody KS, Najbauer J, Terzis AJ (2005) Opinion: The origin of the cancer stem cell: current controversies and new insights. Nat Rev Cancer 5:899-904

Blue J, Weiss L (1981) Electron microscopy of the red pulp of the dog spleen including vascular arrangements, periarterial macrophage sheaths (ellipsoids), and the contractile, innervated reticular meshwork. Am J Anat 161:189-218

Cameron LA, Footer MJ, van Oudenaarden A, Theriot JA (1999) Motility of ActA protein-coated microspheres driven by actin polymerization. Proc Natl Acad Sci USA 96:4908-4913

Chou Y-H, Chien C-T (2002) Scabrous controls ommatidial rotation in the Drosophila compound eye. Dev Cell 3:839-850

Cilia ML, Jackson D (2004) Plasmodesmata form and function. Curr Opin Cell Biol 16:500-506

Csordás A (2006) Mitochondrial transfer between eukaryotic animal cells and its physiologic role. Rejuvenation Res 9:450-454

Cudmore S, Cossart P, Griffiths G, Way M (1995) Actin-based motility of vaccinia virus. Nature 378:636-638

Cudmore S, Reckmann I, Griffiths G, Way M (1996) Vaccinia virus: a model system for actin-membrane interactions. J Cell Sci 109:1739-1747

Demontis F (2004) Nanotubes make big science. PLoS Biol 2:E215

Demontis F, Dahmann C (2007) Apical and lateral cell protrusions interconnect epithelial cells in live Drosophila wing imaginal discs. Dev Dyn 236:3408-3418

Favoreel HW, Van Minnebruggen G, Adriaensen D, Nauwynck HJ (2005) Cytoskeletal rearrangements and cell extensions induced by the US3 kinase of an alphaherpesvirus are associated with enhanced spread. Proc Natl Acad Sci USA 102:8990-8995

Favoreel HW, Van Minnebruggen G, Van de Walle GR, Ficinska J, Nauwynck HJ (2006) Herpesvirus interference with virus-specific antibodies: bridging antibodies, internalizing antibodies, and hiding from antibodies. Vet Microbiol 113:257-263

Freund D, Bauer N, Boxberger S, Feldmann S, Streller U, Ehninger G, Werner C, Bornhäuser M, Oswald J, Corbeil D (2006) Polarization of human hematopoietic progenitors during contact with multipotent mesenchymal stromal cells: effects on proliferation and clonogenicity. Stem Cells Dev 15:815-829

Gallagher KL, Benfey PN (2005) Not just another hole in the wall: understanding intercellular protein trafficking. Genes Dev 19:189-195 
Gerdes H-H, Bukoreshtliev NV, Barroso JF (2007) Tunneling nanotubes: a new route for the exchange of components between animal cells. FEBS Lett 581:2194-2201

Gibson MC, Schubiger G (2000) Peripodial cells regulate proliferation and patterning of Drosophila imaginal discs. Cell 103:343-350

Groothuis TA, Griekspoor AC, Neijssen JJ, Herberts CA, Neefjes JJ (2005) MHC class I alleles and their exploration of the antigenprocessing machinery. Immunol Rev 207:60-76

Guo G-Q, Zheng G-C (2004) Hypotheses for the functions of intercellular bridges in male germ cell development and its cellular mechanisms. J Theor Biol 229:139-146

Gustafson T, Wolpert L (1967) Cellular movement and contact in sea urchin morphogenesis. Biol Rev Camb Philos Soc 42:442-498

Hodneland E, Lundervold A, Gurke S, Tai X-C, Rustom A, Gerdes H$\mathrm{H}$ (2006) Automated detection of tunneling nanotubes in 3D images. Cytometry A 69:961-972

Hsiung F, Ramírez-Weber F-A, Iwaki DD, Kornberg TB (2005) Dependence of Drosophila wing imaginal disc cytonemes on Decapentaplegic. Nature 437:560-563

Jacinto A, Wood W, Balayo T, Turmaine M, Martinez-Arias A, Martin P (2000) Dynamic actin-based epithelial adhesion and cell matching during Drosophila dorsal closure. Curr Biol 10:1420-1426

Jolly C, Sattentau QJ (2004) Retroviral spread by induction of virological synapses. Traffic 5:643-650

Jolly C, Kashefi K, Hollinshead M, Sattentau QJ (2004) HIV-1 cell to cell transfer across an Env-induced, actin-dependent synapse. J Exp Med 199:283-293

Kajstura J, Leri A, Bolli R, Anversa P (2006) Endothelial progenitor cells: neovascularization or more? J Mol Cell Cardiol 40:1-8

Koyanagi M, Brandes RP, Haendeler J, Zeiher AM, Dimmeler S (2005) Cell-to-cell connection of endothelial progenitor cells with cardiac myocytes by nanotubes: a novel mechanism for cell fate changes? Circ Res 96:1039-1041

Kullberg RW, Lentz TL, Cohen MW (1977) Development of the myotomal neuromuscular junction in Xenopus laevis: an electrophysiological and fine-structural study. Dev Biol 60:101-129

La Boissière S, Izeta A, Malcomber S, O'Hare P (2004) Compartmentalization of VP16 in cells infected with recombinant herpes simplex virus expressing VP16-green fluorescent protein fusion proteins. J Virol 78:8002-8014

Levchenko A, Mehta BM, Niu X, Kang G, Villafania L, Way D, Polycarpe D, Sadelain M, Larson SM (2005) Intercellular transfer of P-glycoprotein mediates acquired multidrug resistance in tumor cells. Proc Natl Acad Sci USA 102:1933-1938

Magalhães AC, Baron GS, Lee KS, Steele-Mortimer O, Dorward D, Prado MAM, Caughey B (2005) Uptake and neuritic transport of scrapie prion protein coincident with infection of neuronal cells. J Neurosci 25:5207-5216

Miaczynska M, Pelkmans L, Zerial M (2004) Not just a sink: endosomes in control of signal transduction. Curr Opin Cell Biol 16:400-406

Miller J, Fraser SE, McClay D (1995) Dynamics of thin filopodia during sea urchin gastrulation. Development 121:2501-2511

Misgeld T, Burgess RW, Lewis RM, Cunningham JM, Lichtman JW, Sanes JR (2002) Roles of neurotransmitter in synapse formation: development of neuromuscular junctions lacking choline acetyltransferase. Neuron 36:635-648

Norcross MA (1984) A synaptic basis for T-lymphocyte activation. Ann Immunol (Paris) 135D:113-134

Önfelt B, Davis DM (2004) Can membrane nanotubes facilitate communication between immune cells? Biochem Soc Trans 32:676678

Önfelt B, Nedvetzki S, Yanagi K, Davis DM (2004) Cutting edge: Membrane nanotubes connect immune cells. J Immunol 173:1511-1513
Önfelt B, Nedvetzki S, Benninger RK, Purbhoo MA, Sowinski S, Hume AN, Seabra MC, Neil MA, French PM, Davis DM (2006) Structurally distinct membrane nanotubes between human macrophages support long-distance vesicular traffic or surfing of bacteria. J Immunol 177:8476-8483

Paul WE, Seder RA (1994) Lymphocyte responses and cytokines. Cell 76:241-251

Ramírez-Weber F-A, Kornberg TB (1999) Cytonemes: cellular processes that project to the principal signaling center in Drosophila imaginal discs. Cell 97:599-607

Ratajczak MZ, Kucia M, Dobrowolska H, Wanzeck J, Reca R, Ratajczak J (2006) Emerging concept of cancer as a stem cell disorder. CEJB 1:73-87

Raucher D, Sheetz MP (1999) Characteristics of a membrane reservoir buffering membrane tension. Biophys J 77:1992-2002

Ribeiro C, Ebner A, Affolter M (2002) In vivo imaging reveals different cellular functions for FGF and Dpp signaling in tracheal branching morphogenesis. Dev Cell 2:677-683

Ritzenthaler S, Chiba A (2003) Myopodia (postsynaptic filopodia) participate in synaptic target recognition. J Neurobiol 55:31-40

Ritzenthaler S, Suzuki E, Chiba A (2000) Postsynaptic filopodia in muscle cells interact with innervating motoneuron axons. Nat Neurosci 3:1012-1017

Rørth P (2003) Communication by touch: role of cellular extensions in complex animals. Cell 112:595-598

Ruiz-Medrano R, Xoconostle-Cazares B, Kragler F (2004) The plasmodesmatal transport pathway for homeotic proteins, silencing signals and viruses. Curr Opin Plant Biol 7:641-650

Rustom A, Saffrich R, Markovic I, Walther P, Gerdes H-H (2004) Nanotubular highways for intercellular organelle transport. Science 303:1007-1010

Sato M, Kornberg TB (2002) FGF is an essential mitogen and chemoattractant for the air sacs of the Drosophila tracheal system. Dev Cell 3:195-207

Sherer NM, Lehmann MJ, Jimenez-Soto LF, Horensavitz C, Pypaert M, Mothes W (2007) Retroviruses can establish filopodial bridges for efficient cell-to-cell transmission. Nat Cell Biol 9:310-315

Sol-Foulon N, Sourisseau M, Porrot F, Thoulouze M-I, Trouillet C, Nobile C, Blanchet F, di Bartolo V, Noraz N, Taylor N, Alcover A, Hivroz C, Schwartz O (2007) ZAP-70 kinase regulates HIV cell-to-cell spread and virological synapse formation. Embo J 26:516-526

Sowinski S, Jolly C, Berninghausen O, Purbhoo MA, Chauveau A, Köhler K, Oddos S, Eissmann P, Brodsky FM, Hopkins C, Önfelt B, Sattentau Q, Davis DM (2008) Membrane nanotubes physically connect $\mathrm{T}$ cells over long distances presenting a novel route for HIV-1 transmission. Nat Cell Biol 10:211-219

Spees JL, Olson SD, Whitney MJ, Prockop DJ (2006) Mitochondrial transfer between cells can rescue aerobic respiration. Proc Natl Acad Sci USA 103:1283-1288

Stinchcombe JC, Bossi G, Booth S, Griffiths GM (2001) The immunological synapse of CTL contains a secretory domain and membrane bridges. Immunity 15:751-761

Sun M, Graham JS, Hegedüs B, Marga F, Zhang Y, Forgacs G, Grandbois M (2005) Multiple membrane tethers probed by atomic force microscopy. Biophys J 89:4320-4329

Tysnes BB, Bjerkvig R (2007) Cancer initiation and progression: involvement of stem cells and the microenvironment. Biochim Biophys Acta 1775:283-297

Vidulescu C, Clejan S, O'Connor KC (2004) Vesicle traffic through intercellular bridges in DU 145 human prostate cancer cells. J Cell Mol Med 8:388-396

Vignjevic D, Montagnac G (2008) Reorganisation of the dendritic actin network during cancer cell migration and invasion. Semin Cancer Biol 18:12-22 
Watkins SC, Salter RD (2005) Functional connectivity between immune cells mediated by tunneling nanotubules. Immunity 23:309-318

Williams GS, Collinson LM, Brzostek J, Eissmann P, Almeida CR, McCann FE, Burshtyn D, Davis DM (2007) Membranous structures transfer cell surface proteins across NK cell immune synapses. Traffic 8:1190-1204
Wood W, Jacinto A, Grose R, Woolner S, Gale J, Wilson C, Martin P (2002) Wound healing recapitulates morphogenesis in Drosophila embryos. Nat Cell Biol 4:907-912

Zhu D, Tan KS, Zhang X, Sun AY, Sun GY, Lee JC (2005) Hydrogen peroxide alters membrane and cytoskeleton properties and increases intercellular connections in astrocytes. J Cell Sci 118:3695-3703 